\title{
Komitmen pemerintah daerah dalam pemanfaatan hasil-hasil penelitian pada Badan Penelitian dan Pengembangan Provinsi Nusa Tenggara Timur
}

\section{Commitment of local government in utilizing research results at the East Nusa Tenggara Province Research and Development Agency}

\author{
Dalmasius Naif ${ }^{\mathrm{a}, *}$, Aprianus P. R. Modena ${ }^{\mathrm{a}}$, \\ ${ }^{a}$ Badan Penelitian dan Pengembangan Daerah Provinsi NTT
}

* Corresponding author: Dalmasius Naif

E-mail: dalmanmilan@gmail.com

Naskah Diterima : 26 Agustus 2019; Di-review : 29 Agustus 2019; Dimuat: 31 Agustus 2019

DOI :

Copyright @FLOBAMORA 2019

\begin{abstract}
The concentration of this research is directed at efforts to analyze the commitment of the Regional Government in the utilization of NTT Province Balitbangda research results in the last five years (2013-2017) and analyze the driving and inhibiting factors in the utilization of NTT Province Balitbangda research results in the formulation of provincial regional development policies NTT. This research was conducted in the NTT provincial government scope using a qualitative approach. Informants were selected purposively and data collection methods used observation, interview and literature study techniques. Data analysis uses descriptive analysis. The conclusion of this study can be seen that the results of research conducted by the NTT provincial Balitbangda as many as 25 titles. The source of research funding comes from DPA Balitbangda Prov. NTT. The conclusion from this study was found 3 important dimensions related to the commitment of local governments in the use of Balitbangda research results as follows: there is high confidence in the goals of the organization through the establishment of regional research and development institutions, the willingness to allocate sufficient budget for research activities, willingness to distribute resources the power of researchers in these organizations, and there is a strong willingness to utilize the results of research conducted by the Balitbangda in the formulation and implementation of regional policies, programs and activities. For this reason, there is a need for a commitment from the regional government to utilize the results of the Balitbangda research, increase the allocation of research budgets, improve the quality of research, publish research results, and enhance cooperation with other academic institutions in the form of making recommendations and higher quality policy papers.
\end{abstract}

Keywords : Regional Government Commitments; Utilization of Research Results; Regional Government Budget Implementing Documents; East Nusa Tenggara; Research Budget.

\begin{abstract}
Abstrak
Konsentrasi penelitian ini diarahkan pada upaya untuk menganalisis komitmen Pemerintah Daerah dalam pemanfaatan hasil-hasil penelitian Balitbangda Provinsi NTT dalam kurun waktu lima tahun terkhir (2013-2017). dan menganalisis faktor pendorong dan penghambat pemanfaatan hasil-hasil penelitian Balitbangda Provinsi NTT dalam perumusan kebijakanpembangunan daerah provinsi NTT . Penelitian ini dilakukan pada lingkup pemerintah Provinsi NTT mengunakan pendekatan kualitatif. Informan yang dipilih secara purposif dan metode pengumpulan data menggunakan teknik observasi,
\end{abstract}


wawancara dan studi pustaka. Analisis data menggunakan analisis deskriptif. Kesimpulan penelitian ini dapat diketahui bahwa hasil penelitian yang dilakukan oleh balitbangda provinsi NTT sebanyak 25 judul. Sumber dana penelitian berasal dari DPA Balitbangda Prov. NTT. Kesimpulan dari penelitian ini ditemukan 3 dimensi penting terkait komitmen pemerintah daerah dalam pemanfaatan hasil penelitian Balitbangda sebagai berikut;adanya kepercayaan yang tinggi terhadap tujuan organisasi melalui pembentukan lembaga penelitian dan pengembangan daerah, adanya kesediaan untuk mengalokasikan anggaran yang cukup untuk kegiatan penelitian, kesediaan untuk mendistribusikan sumber daya peneliti pada organisasi tersebut, dan adanya kemauan yang kuat dalam pemanfaatan hasil penelitian yang dilakukan oleh balitbangda dalam perumusan dan pelaksanaan kebijakan, program dan kegitan daerah. Untuk itu perlu adanya komitmen pemerintah daerah untuk memanfaatkan hasil-hasil penelitian balitbangda, meningkatkan alokasi anggaran penelitian, meningkatkan kualitas penelitian, mempublikasikan hasil-hasil penelitian, dan meningkatkan kerja sama dengan lembaga akademis lainnya dalam rangka pembuatan rekomendasi dan kertas kebijakan yang lebig berkualitas.

Keywords : Komitmen Pemerintah Daerah; Pemanfaatan Hasil Penelitian; Dokumen Pelaksana Anggaran Pemerintah Daerah; Nusa Tenggara Timur; Anggaran Penelitian.

\section{Pendahuluan}

Penelitian pada hakikatnya adalah kegiatan yang dilakukan menurut kaidah dan metode ilmiah secara sistematis untuk memperoleh informasi, data dan keterangan yang berkaitan dengan pemahaman dan pembuktian kebenaran atau ketidakbenaran suatu asumsi dan/atau hipotesis. Dengan demikian, penelitian merupakan usaha untuk menjawab pertanyaan reflektif bagaimana manusia dapat mengetahui kebenaran dari sesuatu. Dalam konteks penyelenggaraan Pemerintahan, penelitian memiliki peran yang begitu penting dan strategis sebagai upaya permulaan untuk mengidentifikasi adanya masalah/hambatan, dan kekuatan yang berkaitan dengan perumusan dan pelaksanaan kebijakan agar kebijakan tersebut berkualitas, objektif, efektif, dan akuntabel (Brown, 2014; Carr and Lapp, 2009; Daviter, 2015; Gambrill, 2006; Dunlop and Radaelli, 2018).

Dengan mempertimbangkan pentingnya penelitian dan pengembangan dalam penyelenggaraan Pemerintahan (Duboy, 2014; Gambrill, 2006; Hank Jenkins-Smith et al., 2018; Kapucu et al., 2017; Landry et al., 2003; Lohr et al., 2013, Lomas, 2000) maka secara regulative Pemerintah telah menetapkan kegiatan kelitbangan di tangani oleh Badan Penelitian dan Pengembangan Daerah Provinsi NTT yang terangkum dalam Peraturan Daerah Provinsi NTT Nomor 09 Tahun 2016 tentang Pembentukan dan Susunan Perangkat Daerah Provinsi NTT, pada pasal 3 (c) point 5 yang menegaskan bahwa "urusan penelitian dan pengembangan daerah dilaksanakan oleh Badan Penelitian dan Pengembangan Daerah Provinsi NTT". Amanat pasal 3 (c) point 5 tersebut sejalan dengan Surat Edaran Menteri Dalam Negeri No: 070/3521/SJ tentang Penguatan Penelitian dan Pengembangan Daerah yang pada poin 1 (b) menegaskan bahwa "Penyelenggaraan kelitbangan yang sebelumnya tersebar diberbagai perangkat daerah, dilaksanakan secara satu pintu oleh perangkat litbang daerah termasuk kegiatan penyiapan naskah akademis/pokok pikiran dalam menindak lanjuti program legislasi daerah.
Dalam konteks pemahaman sebuah organisasi, hubungan antara Pemerintah Daerah Provinsi NTT dan Balitbangda Provinsi NTT adalah hubungan analogis antara Organisasi dan Individu serta tugas dan fungsi Balitbangda yang diamanatkan dalam Peraturan Daerah Nomor 9 Tahun 2016 tentang Pembentukan dan Susunan Perangkat Daerah, sebagai sebuah komitmen yang dibangun oleh pemerintah daerah sebagai organisasi dan Balitbangda sebagai individu dalam organisasi (Ljungholm, 2016; Mosley, 2014, MacCoun, 1998, Robichau, 2011; Robichau and Lynn, 2009; Shea, 2011). Komitmen ini dibangun sebagai tindaklanjut atas tujuan organisasi yang dalam konteks ini adalah visi dan misi Gubernur sebagai pimpinan daerah. Selain itu tugas dan fungsi Balitbangda adapula komitmen pemerintah daerah yang ditunjukan dengan kesediaan mengalokasikan anggaran penelitian, mendistribusi sumber daya peneliti dan penguatan organisasi litbang melalui pengembangan kapasitas yang meliputi organisasi, individu dan kebijakan (Saetren, 2005; Sawitri et al., 2016; Stevens, 2011; Ursacescu and Cioc, 2012; Walters et al., 2000). Komitmen pemda tersebut ditunjukkan melalui kesediaan menagalokasikan dana penelitian dalam kurun waktu 5 tahun (2013-2017). Rincian anggaran penelitian beserta penyerluasan informasi hasil-hasil penelitian sebgai berikut; 1) Tahun 2013 (Rp.219.032.400 dari total dana Balitbangda Rp.4.490.350.000), 2) tahun 2014 (Rp.735.628.400 dari total dana Rp.5.014.136.650), 3) tahun 2015 (Rp. 1.854.672.900 dari total dana $\mathrm{Rp}$ 7.242.366.000), 4), tahun 2016 (Rp.1.514.689.950 dari total dana Rp.7.093.528.000), 5) tahun 2017 (Rp.1.881.194.500 dari total dana Rp7.469.334.000). selanjutnya pemda juga bersedia mengangkat tenaga fungsional peneliti sebanyak 17 orang dengan kualifikasi pendidikan masing-masing namun besaran tunjangan yang diberikan relative sama dengan pejabat structural eselon III.

Secara spesifik, tugas dan fungsi Balitbangda Provinsi NTT sebagai pembantu Gubernur dalam menjalankan tugas penelitian dan pengembangan sesuai Peraturan Daerah (Perda) Nomor 9 tahun 
2016 tentang Pembentukan dan Susunan Perangkat Daerah yaitu mengkoordinasikan perumusan kebijakan teknis kegiatan kelitbangan meliputi kesekretariatan, pemerintahan dan pengkajian perundangan, sosial dan kependudukan, ekonomi dan pembangunan serta inovasi dan teknologi berdasarkan ketentuan dan prosedur yang berlaku agar terwujudnya kesediaan aparatur pemerintah yang memiliki kompetensi serta tersedianya bank data dan rekomendasi hasil kelitbangan dalam perencanaan pembangunan daerah. Selain itu, Balitbangda Provinsi NTT juga berperan sebagai think tank dalam mengkritisi berbagai permasalahan yang berkembang untuk selanjutnya merumuskan berbagai kebijakan pemerintah daerah, optimalisasi pemanfaatan potensi sumberdaya daerah, dan kebijakan-kebijakan strategis lainnya terkait dengan pelaksanaan pembangunan, yang akhirnya bermuara pada terlaksananya percepatan otonomi daerah. Sebagai lembaga professional dan bersifat akademis Balitbangda Provinsi NTT dituntut untuk mampu melakukan interaksi dan kerjasama dengan berbagai pihak yang terkait dengan tugas dan fungsinya.

Hasil-hasil penelitian yang dilakukan oleh Balitbangda provinsi NTT sebagai bentuk pelaksanaan tupoksi sebagaimana amanat Peraturan daerah Nomor 9 Tahun 2016 merupakan input bagi proses perencanaan pembangunan daerah (Robichau and Lynn, 2009; MacCoun, 1998; Ljungholm, 2016; Lomas, 2000). Dengan kata lain pelaksanaan tugas dan fungsi Balitbangda berhubungan dengan wacana perencanaan berbasis penelitian dan kebijakan berbasis penelitian (policy based on reseach) (Shea, 2011; Lavis et al., 2003; Landry et al., 2003; Daviter, 2015; Carr and Lapp, 2009). Terdapat 25 hasil penelitian yang dilakukan oleh balitbangda dalam kurun waktu 5 (lima) tahun terakhir. Hasil penelitian ini merupakan kesediaan Balitbangda untuk bekerja secara optimal demi kepentingan organisasi (bdk.Luthans, 1992). Dengan itu, Balitbangda telah menunjukkan komitmen yang dibangun bersama dengan Pemerintah Daerah.

Meskipun sudah banyak produk penelitian yang dihasilkan oleh Balitbangda Provinsi NTT, namun pada kenyataannya bahwa dalam dinamika perencanaan pembangunan daerah sejumlah Perangkat Daerah belum menggunakan hasil-hasil penelitian Balitbangda dalam penumusan kebijakan, program dan kegiatan perangkat daerah. Sejumlah Perangkat Daerah masih terjebak dalam fenomena rutinitas dan dalam menara gading ego sektoral dalam perumusan kebijakan, program dan kegiatan Perangkat Daerah. Hasil-hasil penelitian Balitbangda yang telah disampaikan kepada Perangkat Daerah terkait dalam bentuk Ringkasan Penelitian atau kertas kebijakan (Policy Brief) belum diacuh dalam penentuan program dan kegiatan Perangkat Daerah tersebut.
Realitas ini menunjukkan masih lemahnya komitmen Pemerintah Daerah dalam menindaklanjuti komitmen bersama yang telah disepakati bersama sebagaimana telah dituangkan Tugas Pokok dan Fungsi Balitbangda seturut amanat Peraturan Daerah Nomor 9 Tahun 2016. Pemerintah daerah sebagai suatu organisasi dalam hubungannya dengan Balitbangda sebagai salah satu individu organisasi dalam mewujutkan tujuan organisasi yang telah dibangun berdasarkan tupoksinya belum berkomitmen penuh dalam memanfaatkan hasil-hasil penelitiannya (Daviter, 2015; Brown, 2014; Saetren, 2005; Stevens, 2011). Oleh karenanya, penting untuk dilakukan penelitian untuk menemukan faktor-faktor penyebab masih lemahnya komitmen pemerintah daerah dalam menindaklanjuti hasil-hasil penelitian Balitbangda dan merumuskan langkah-langkah strategis untuk menguatkan komitmen pemerintah daerah tersebut. Berdasarkan latar belakang tersebut di atas maka rumusan masalah dalam pengkajian ini adalah sebagai berikut;1) Bagaimanakah komitmen Pemerintah Daerah Provinsi NTT memanfaatkan hasil-hasil penelitian Balitbangda Provinsi NTT? 2) Apa saja faktor pendorong dan faktor penghambat pemanfaatan hasil-hasil penelitian Balitbangda Provinsi NTT dalam perumusan kebijakan pembangunan daerah Provinsi NTT?

\section{Metode}

Desain penelitian ini adalah diskriptif atau eksploratif, untuk menggali data sesuai apa adanya. Penelitian ini mengambil lokasi di lingkup pemerintah daerah provinsi NTT. Informan penelitian diambil secara purposif berdasarkan pertimbangan pemanfaatan hasil penelitian oleh SKPD terkait. Oleh karena penelitian dengan dana tersebut diharapkan dapat menghasilkan luaran seperti rekomendasi dan kertas kebijakan. Metode pengambilan data dilakukan dengan metode observasi, wawancara, maupun studi pustaka. Instrumen yang digunakan dalam penelitian ini adalah berupa daftar pertanyaan wawancara untuk menjaring semua informasi tentang pemanfaatan hasil-hasil penelitian yang telah dilakukan. Untuk mendapatkan informasi tersebut akan dibuat yang berisi: identitas peneliti, judul Penelitian, Jumlah dana, Luaran Penelitian, yang meliputi : rekomendasi dan kertas kebijakan. Kesulitan yang dihadapi SKPD terkait dalam pemanfaatan hasil penelitian pada umumnya. Saran peneliti untuk meningkatkan kualitas hasil Balitbangda. Teknik analisis data yang digunakan dalam penelitian ini adalah dengan analisis diskriptif.

\section{Hasil dan Pembahasan}

Data hasil penelitian yang dilakukan oleh Balitbangda Provinsi NTT dalam kurun waktu lima tahun terakhir terdapat dua puluh lima penelitian 
yang dapat di rinci sebagai berikut; tahun 2013 (4 Penelitian), tahun 2014 (2 penelitian), tahun 2015 (7 penelitian), tahun 2016 (4 penelitian) dan tahun 2017 (8 penelitian). Sumber dana penelitian tersebut berasal dari pagu anggaran Dokumen Pelaksana Anggaran Satuan Kerja Perangkat Daerah Badan Penelitian dan Pengembangan Daerah Provinsi NTT. Keluaran hasil penelitian Balitbangda berupa rekomendasi dan kertas kebijakan diberikan kepada perangkat daerah yang bersentuhan dengan hasil penelitian yang dilakukan Balitbangda khususnya Badan Perencanaan dan Pembangunan Daerah Provinsi NTT untuk selanjutnya digunakan diacuh dalam perumasan dan pelaksanaan kebijakan, program dan kegiatan perangkat daerah tersebut berdasarkan standar operating prosedur yang ada.

Hasil penelitian ini menunjukkan bahwa hasil penelitian yang di lakukan oleh balitbangda Provinsi NTT belum dimanfaatkan sama sekali oleh dinas/badan dalam perumusan dan pelaksanaan kebijakan, program dan kegiatan karena kualitas penelitian yang dihasilkan belum teruji, kurangnya informasi tentang data hasil penelitian, dan kurangnya sosialisasi tentang hasil-hasil penelitian yang dilakukan. Selain itu ada hasil penelirian yang dihasilkan balitbangda mau di manfaatkan atau tidak pun tergantung dari kemauan pimpinan daerah dalam hal ini gubernur. Apabila ada permintaan dari pimpinan daerah maka dapat dipakai dalam perumasan program dan kegiatan satuan perangkat daerah.

Berkaitan dengan kualitas penelitian di atas terdapat sejumlah kesulitan yang di temui dalam organisasi balitbangda.

Pemahaman dan pengetahuan Peneliti terhadap substansi penelitian masih terbatas pada tahapan pengetahuan dasar hal ini bisa diukur dari pendidikan maupun pelatihan yang diperoleh peneliti. Lebih dari sebagian peneliti (65\%) berpendidikan S1 dan selebihnya (35\%) berpendidikan S2. Semua peneliti (100\%) baru mengikuti Diklat Peneliti Dasar. Dengan demikian tingkat pengetahuan dan pemahaman substansi penelitian peneliti masih pada level dasar tentunya juga akan berpengaruh besar terhadap hasil-hasil penelitian yang berkualitas sebagai indicator kompetensi (deliverables). Motivasi individu yang dimilik Peneliti juga berdampak pada pencapaian tujuan organisasi dalam hal pencapaian kinerja. Artinya bahwa, ketika Peneliti memiliki kepentingan individu seperti pengembangan karir melalui prestasi yang diraih dengan sendirinya penelitian yang menjadi tugas dan tanggungjawabnya terselesaikan dengan baik sesuai waktunya.

Terkesan, Balitbangda merupakan organisasi "buangan" bagi pejabat structural dan munculnya image bahwa Balitbangda bukan tempat yang menjanjikan untuk meningkatkan kesejahteraan PNS karena selain anggarannya kecil juga seluruh kegiatan penelitian dilakukan Peneliti sehingga pejabat structural maupun staf kurang mendapat ruang dalam penambahan penghasilan maupun kesempatan berkarya dengan anggapan penelitian tidak terlalu bermanfaat bagi mereka secara pribadi maupun bagi masyarakat.

Tabel 1. Data hasil penelitian dalam lima tahun terakhir (2013-2017)

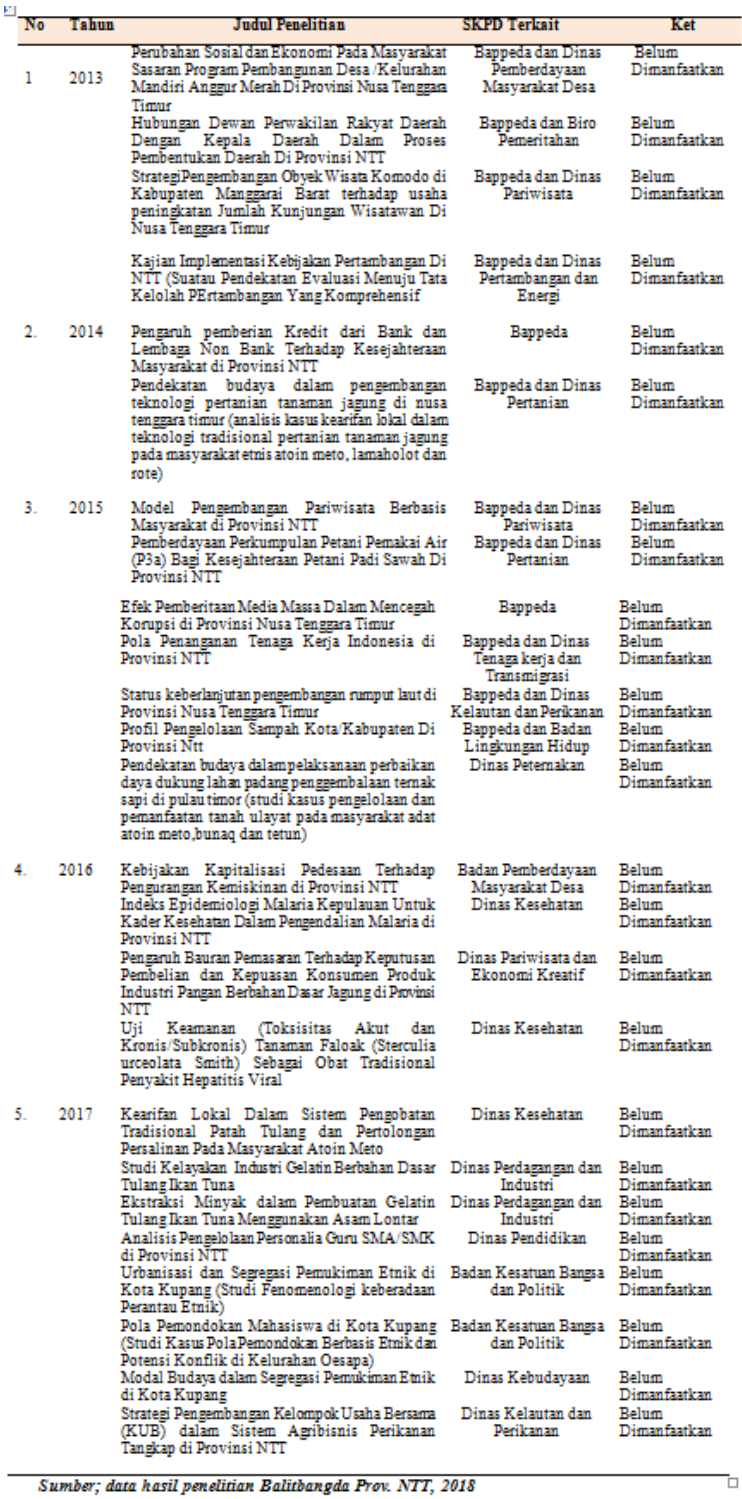

Motivasi individu Peneliti yang berdampak pada pencapaian kinerja Balitbangda Provinsi NTT adalah sesuatu yang baik paling tidak merupakan langkah sebagai modal meskipun harus diakui bahwa hasilhasil penelitian Balitbangda Provinsi NTT belum berkontribusi secara nyata yang dimanfaatkan oleh masyarakat. Hal ini jugalah yang menjadi persoalan Balitbangda Provinsi NTT. Penelitian yang dilakukan Peneliti dianggap bukanlah sesuatu yang mudah karena seorang peneliti harus melalui beberapa tahapan dengan intervensi structural yang cukup berpengaruh dalam penentuan personil Peneliti untuk memimpin kelompok penelitian. Sehingga beberapa Peneliti yang tidak memperoleh kesempatan terlihat kurang termotivasi melakukan penelitian. Peneliti 
yang kurang termotivasi menjadi tertutup dan cendrung tidak berkomunikasi dengan pimpinan, rekan kerja dan pihak lainnya yang memiliki pemikiran-pemikiran ilmiah sehingga terkesan bidang - bidang memanfaatkan Peneliti yang dianggap "mengganggur" dengan memanfaatkan waktu lowongnya untuk membantu mengerjakan pekerjaan-pekerjaan administratif sedangkan bagi Peneliti yang memiliki motivasi menganggap pekerjaan-pekerjaan lainnya diluar penelitian akan sangat mengganggu pekerjaan utamanya sebagai seorang Peneliti.

Peneliti harus memiliki karakter yang unggul yang berkontribusi pada pembangunan daerah dan upaya memanfaatkan hasil penelitian untuk kesejahteraan masyarakat. Adanya komitmen Peneliti untuk melaksanakan tugas dan tanggungjawab secara baik jika tidak tidak ditunjang dengan pengetahuan, ketrampilan maupun karakter untuk unggul akan berkontribusi pada output penelitian.

\section{Kesimpulan}

Berdasarkan temuan dan pembahasan di atas, maka penelitian ini menyimpulkan bahwa hasil penelitian yang dilakukan oleh Balitbangda provinsi NTT berupa rekomendasi dan kertas kebijakan belum dimanfaatkan karena dalam perumusan kebijakan, program dan kegiatan skpd terkait tidak mengacuh pada hasil-hasil yang di berikan oleh karena rekomendasi dan kertas kebijakan masih bersifat umum, rendahnya sumber daya peneliti, anggaran penelitian masih sangat minim.

Upaya yang dilakukan dalam rangka pemanfaatan hasil-hasil penelitian sebagai bentuk komitmen pemerintah daerah adalah melalui peningkatan kualitas mutu penelitian melalui, sumber daya peneliti, rekomendasi yang diberikan dilakukan oleh para pakar dan alokasi dana yang cukup, penyerbarluasan informasi penelitian lewat publikasi hasil-hasil penelitian pada jurnal akreditasi.

Dari hasil penelitian tersebut maka penulis menyarankan agar organisasi Balitbangda harus Menumbuhkan motivasi individu melalui diskusidiskusi ilmiah secara rutin dalam internal Balitbangda Provinsi NTT dan berkomitmen untuk terus belajar pengetahuan-pengetahuan ilmiah dalam upaya pengembangan kapasitas individu.Balitbangda Provinsi NTT perlu membuat Rencana Induk Kelitbangan dalam jangka waktu 5 (lima) tahun yang terintegrasi dalam RPJMD 2018-2023. Perlunya kerja sama penelitian dengan universitas yang ada di Provinsi NTT sehingga output berupa rekomendasi dalam kertas kebijakan lebih berkualitas. Dengan demikian hasil-hasil penelitian tersebut dapat digunakan oleh pemerintah daerah dalam perumusan kebijakan pembangunan daerah.

\section{Ucapan Terima Kasih (Acknowledgments)}

Terima kasih kepada Badan Penelitian dan Pengembangan Daerah Provinsi NTT yang telah memberi akses untuk mendapatkan data.

\section{Referensi}

Brown, C. 2014, "Advancing policy makers' expertise in evidence-use: A new approach to enhancing the role research can have in aiding educational policy development", Journal of Educational Change, vol. 15, no. 1, pp. 19-36.

Carr, A.N. \& Lapp, C.A. 2009, "ORGANIZATION THEORY AND ORGANIZATION BEHAVIOR: THROUGH THE LENS OF PSYCHODYNAMICS", International Journal of Organization Theory and Behavior, vol. 12, no. 3, pp. 381-405.

Daviter, F. 2015, "The political use of knowledge in the policy process", Policy Sciences, vol. 48, no. 4, pp. 491-505.

Dunlop, C.A. \& Radaelli, C.M. 2018, "Does Policy Learning Meet the Standards of an Analytical Framework of the Policy Process?", Policy Studies Journal, vol. 46, pp. S48-S68.

Dubov, A. 2014, "The concept of governance in dual-use research", Medicine, health care, and philosophy, vol. 17, no. 3, pp. 447-457.

Gambrill, E. 2006, "Evidence-Based Practice and Policy: Choices Ahead", Research on Social Work Practice, vol. 16, no. 3, pp. 338-357.

Gambrill, E. 1999, "Evidence-based practice: An alternative to authority-based practice", Families in Society, vol. 80, no. 4, pp. 341-350.

Hank Jenkins-Smith, Krutz, J., Carlson, N. \& Weible, C. 2018, "The 2018 Public Policy Yearbook: Recent Trends in Public Policy Research", Policy Studies Journal, vol. 46, pp. S4-S12.

Hank Jenkins-Smith, Krutz, J., Carlson, N. \& Weible, C. 2018, "The 2018 Public Policy Yearbook: Recent Trends in Public Policy Research", Policy Studies Journal, vol. 46, pp. S4-S12.

Kapucu, N., Hu, Q. \& Khosa, S. 2017, "The State of Network Research in Public Administration", Administration \& Society, vol. 49, no. 8, pp. 1087-1120.

Landry, R., Lamari, M. \& Amara, N. 2003, "The extent and determinants of the utilization of university research in government agencies", Public administration review, vol. 63, no. 2, pp. 192.

Lavis, J.N., Robertson, D., Woodside, J.M., McLeod, C.B. \& Abelson, J. 2003, "How can research organizations more effectively transfer research knowledge to decision makers?", The Milbank quarterly, vol. 81, no. 2, pp. 221-248. 
Lohr, F., Hallensleben, S. \& Beyer-Kutzner, A. 2013, "Strategic dialogues for research policy making in Germany", Foresight : the Journal of Futures Studies, Strategic Thinking and Policy, vol. 15, no. 1, pp. 19-28.

Lomas, J. 2000, "ESSAY: Using 'Linkage And Exchange' To Move Research Into Policy At A Canadian Foundation", Health affairs, vol. 19, no. 3, pp. 236-240.

Ljungholm, D.P. 2016, "EFFECTIVE SERVANT LEADERSHIP BEHAVIOR IN ORGANIZATIONS", Linguistic and Philosophical Investigations, vol. 15, pp. 239245.

Mosley, J.E. 2014, "Collaboration, Public-Private Intermediary Organizations, and the Transformation of Advocacy in the Field of Homeless Services", American Review of Public Administration, vol. 44, no. 3, pp. 291.

MacCoun, R.J. 1998, "Biases in the interpretation and use of research results", Annual Review of Psychology, vol. 49, pp. 259-87.

Robichau, R.W. 2011, "The Mosaic of Governance: Creating a Picture with Definitions, Theories, and Debates", Policy Studies Journal, vol. 39, pp. 113-131.

Robichau, R.W. \& Lynn, L.E. 2009, "The Implementation of Public Policy: Still the Missing Link", Policy Studies Journal, vol. 37, no. 1, pp. 21-36.

Shea, J. 2011, "Taking Nonprofit Intermediaries Seriously: A Middle-Range Theory for Implementation Research", Public administration review, vol. 71, no. 1, pp. 57-66.

Saetren, H. 2005, "Facts and Myths about Research on Public Policy Implementation: Out-of-Fashion, Allegedly Dead, But Still Very Much Alive and Relevant", Policy Studies Journal, vol. 33, no. 4, pp. 559-582.

Sawitri, Dyah,S.E., M.M., Suswati, Endang,S.E., M.S. \& Huda, Khasbulloh,S.E., M.M. 2016, "THE IMPACT OF JOB SATISFACTION, ORGANIZATION COMMITMENT, ORGANIZATION CITIZENSHIP BEHAVIOR (OCB) ON EMPLOYEES' PERFORMANCE", International Journal of Organizational Innovation (Online), vol. 9, no. 2, pp. 24-45.

STEVENS, A. 2011, "Telling Policy Stories: An Ethnographic Study of the Use of Evidence in Policy-making in the UK", Journal of social policy, vol. 40, pp. 237-255.

Ursacescu, M. \& Cioc, M. 2012, "The Economic Intelligence Practices and Their Impact on the Organization's Strategic Behavior", Revista de Management Comparat International, vol. 13, no. 2, pp. 211-223.

Walters, L.C., Aydelotte, J. \& Miller, J. 2000, "Putting more public in policy analysis", Public administration review, vol. 60, no. 4, pp. 349359. 